\title{
Effect of Quinoa (Chenopodium quinoa) and Canahua Wholemeals (Chenopodium pallidicaule) on Pasting Behavior of Wheat Flour
}

\author{
Ivan Švec ${ }^{1 *}$, Marie Hrušková ${ }^{1}$, Rasa Kapačinskaitè ${ }^{2}$ and Tatána Hofmanová ${ }^{1}$ \\ ${ }^{1}$ Department of Carbohydrates and Cereals, University of Chemistry and Technology Prague, Technická 5, 16628 \\ Prague 6 - Dejvice, Czech Republic \\ ${ }^{2}$ Kaunas University of Technology, K. Donelaičio 73, 44249 Kaunas, Lithuania \\ Email: Ivan.Svec@vscht.cz
}

\begin{abstract}
Technological potential of four wheat-quinoa and wheat-canahua flour composites was evaluated in terms of pasting behavior. Wheat flour values of Zeleny sedimentation and Falling Number tests were decreased about $10 \%$. Amylograph results were affected by low amylases activity in wheat flour as well as by high absorption capacity of canahua and quinoa - samples differed partly in temperature of gelatinization beginning. RVA profiles of pure flours differed clearly - both alternative materials did not demonstrate viscosity peak and differed in starch retrogradation rate during heating and cooling phase of the test. In combination with wheat flour, the profiles were influenced softly. Statistically significant differentiation was observed in the Peak Viscosities - the higher enhancement level, the lower value, as recorded especially for wheat-canahua blends. Principal component analysis verified a key importance of temperature of gelatinization beginning, viscosity maximum and proper temperature - RVA apparatus may serve as the first quick method for pasting behavior description.
\end{abstract}

Keywords: Wheat composite flour, non-traditional crop, gelatinization, rheological properties, retrogradation

\section{$1 \quad$ Introduction}

The enhancement of wheat flour by forgotten plant materials, called generally as non-traditional, belongs to the current trend in cereal chemistry research and bakery industry. The advantages of such crops usage comprises both innovation of offered final cereal products, and mainly improvement of the nutritional score of cereal products. To such crops, pseudocereals are also ranked, non-grass plants used for human nutrition, producing seeds that can be milled into flour. In terms of botanical classification, that group is heterogeneous, involving amaranth, chia, buckwheat, quinoa etc. The crop Chenopodium quinoa Willd. was known and consumed 5000 years ago in the Andean region of the South America, and as called "mother of grain", it had also religion connotation [1]. Its less known botanic relative is called canahua (kaniwa, baby-quinoa), which has the same usage as quinoa. Fruits of both plant are tiny seeds, consumed as is (i.e. whole) after boiling as soups, or milled to wholemeal flour in form of drinks, porridge or baked into the form of flat-bread. Rosell et al. [2] mentioned a breadmaking usage of other Andean crops kiwicha (Amaranthus caudatus) and tarwi (Lupinus mutabilis), too.

All members of Chenopodiacea family are tolerant to climate, able to grow at altitudes of the seacoast up to approx. $4000 \mathrm{~m}$ in extreme highland environment $[1,3,4]$. Quinoa became world-known plant and food - according to FAO, the main producers are Bolivia, Peru and Ecuador (70,000 tons produced in year 2009 [5]). Quinoa cultivation was spread almost all over the world and now it is bred in more than 70 countries (e.g. France, Sweden, USA, Kenya or India). Similarly to other plants, the main constituent of the quinoa and the canahua seeds are carbohydrates - content in canahua is lower than in quinoa as well as in wheat, too $(63.4 \%, 72.6 \%$ and $78.5 \%$, respectively [4]). In terms of crude fibre, the order of the crops is inversed $(6.1 \%, 4.0 \%$, and $2.5 \%$, respectively), likewise for lipids and minerals (confirmed by Rosell et al. [2]). The proteins content oscillates between 10-18\%, but their amino acid composition is more balanced compared to wheat ones. Quinoa is a good source of lysine and histidine [6]. Both crops 
are characteristic by absence of gluten, although e.g. kaniwa protein contains $4.2-6.0 \%$ prolamins and 9.3-11.4\% glutelins [4]. Bioactive chemicals comprise especially saponins (both sweet and bitter), phenolics, and flavonoids $[1,4]$.

According to previous researches, starch structure differs between quinoa and canahua. In the former case, starch granules are small in diameter (0.6-2.0 $\mu \mathrm{m}[3]$; 1.0-2.5 $\mu \mathrm{m}$ [7]) and have polygonal form. The amylose content is lower than in cereal grains (4-20\%), which allows gelatinization at lower temperatures $\left(50-65{ }^{\circ} \mathrm{C}[7]\right)$. In the latter case, starch granules are presented in bimodal size distribution with also irregular and polygonal shape. The ratio of amylose-to-amylopectin is equal to 15:85 in average [4], and pasting temperature should be higher than for quinoa and wheat.

Description of flour or isolated starch behaviour during heating and cooling may facilitate material application possibilities such as e.g. emulsifier, thickener, stuffing etc. In case of leavened bakery products, it may predict the results of bread baking test and final product shelf life (speed of staling, related to starch retrogradation rate).

The aim of the study was to evaluate the influence of different additions of flour from both nontraditional crops on pasting behaviour of wheat flour, using traditional and modern technique (Falling Number, amylograph and Rapid Visco Analyser). To explore similarities among tested flour and composite flour samples as well as among recorded parameters of pasting, descriptive analysis of variance and multivariate principal component method (PCA) were employed.

\section{$2 \quad$ Materials and Methods}

\subsection{Flour Samples, Blends Preparation}

Basic wheat flour (WF) was delivered by the industrial mill Jaroslav Chochole - Delta located in Prague, and its quality corresponds to average values of the 2016 harvest within the Czech Republic (protein content $13.1 \%$, Zeleny value $40 \mathrm{ml}$, Falling number $422 \mathrm{~s}$ ). With respect to such quality, it fulfilled a premise for fortification by non-traditional, naturally gluten-free plant materials.

Both quinoa and cahanua were bought in specialized food shops in Prague (Country Life CZ and Bylinkuj.cz, respectively) in the form of whole seeds (abbreviations Q and C). To transform them into smooth flour, laboratory blade grinder Concept KM 5001 (Elko Valenta, Czech Republic) was used. Seeds dosage and treatment time count $25 \mathrm{~g}$ and $3.0 \mathrm{~min}$, respectively. Addition levels were selected as 10 and 20 wt. $\%$ on wheat flour base, and composite flour codes combine letters indicating plant raw materials and replacement level of wheat flour (WFQ10, WFQ20; WFC10, WFC20).

Zeleny (Canahua set)

$\square$ Zeleny (Quinoa set)

s Falling Number (Canahua set) $\square$ Falling Number (Quinoa set)

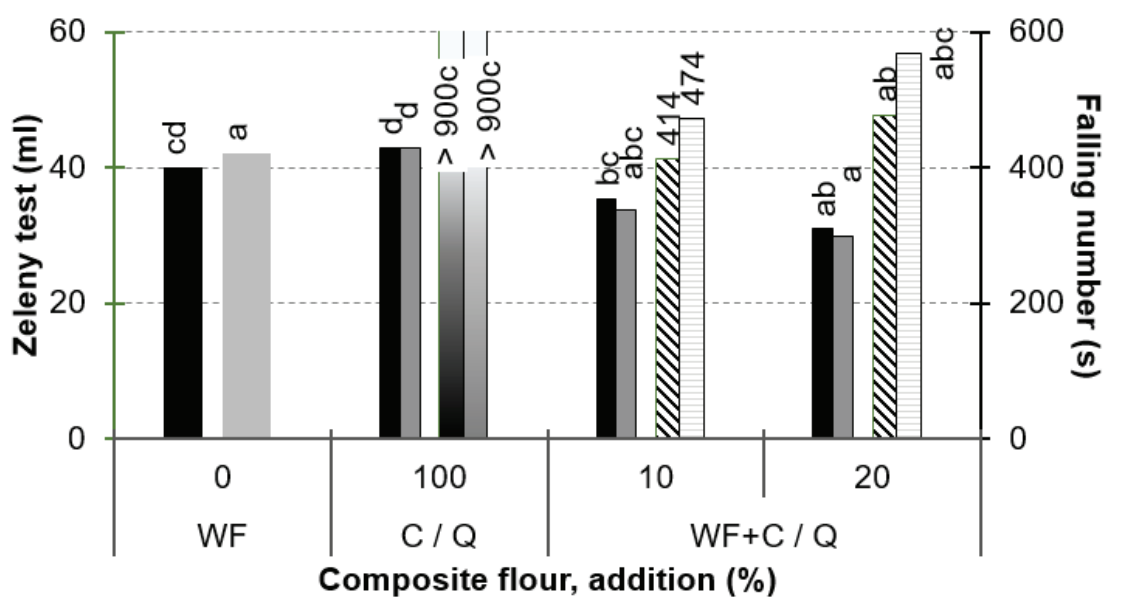

Figure 1. Effect of canahua wholemeal $(\mathrm{C})$ and quinoa wholemeal $(\mathrm{Q})$ on technological quality of wheat flour (WF). 


\subsection{Flour Samples, Blends Preparation}

Technological quality of prepared flour composites was tested in term of bakery quality of proteins and amylose activity estimation, namely by the Zeleny sedimentation and the Falling Number tests (EN ISO 5529 and 3039 , respectively [8, 9]; measurements in duplicate).

\subsection{Pasting Characteristics of Flour Composite}

During the Falling number proof, polysaccharides pasting was finished in minute, and due to that, detailed description was recorded using two rotational viscometers. A classical approach represents Amylograph Brabender (type AS1; Brabender GmbH \& Co. KG, Duisburg, Germany), and a modern one programmable Rapid Visco Analyser (type 4500; Perten Intruments, Hägersten, Sweden). Both tests were determined according to international standards (norm ICC 126/1 and AACC method 76-21, respectively) in one replication; the methods repeatability was evaluated before, using an independent sample of wheat flour.

\subsection{Data Statistical Treatment}

Influence of quinoa and canahua vs. additions $10 \%$ or $20 \%$ on wheat flour viscous behaviour was compared by Tukey's test (ANOVA on p < 0.05), using Statistica 13.0 software (Statsoft Inc., Tulsa, USA). A complex view in pasting process course may be rendered by multivariate statistical method as principal component analysis (PCA).

\section{$3 \quad$ Results and Discussion}

\subsection{Analytical Quality of Flour and Flour Composites}

In terms of the protein bakery quality, Zeleny values determined for pure quinoa and canahua wholemeals seemed to be comparable with wheat control (twice $43 \mathrm{ml}$ vs. $40 \mathrm{ml}$ ). In the fact, that finding could be attributed to higher water absorption ability of the polysaccharides present in quinoa and canahua [10]. For quinoa flour, Pellegrini et al. determined high swelling capacity without regard to lower water holding capacity [11]. The statement is also supported by comparable decrease of sediment volume in case of the wheat-quinoa bi-composites tested. For samples enhanced to a higher extent, Zeleny values lowering reached approximately $10 \%$ (Fig. 1); such quality change could already have a negative impact on volume of the final bakery products.

For wheat flour, amylases activity was estimated about half lower than technological optimum $250 \mathrm{~s}$ (namely 421 s; Fig. 1). For quinoa and canahua flour, the Falling numbers were unevaluable - after 900 $\mathrm{s}$, the measurement was stopped manually. As could be noticed in the plot, quinoa addition caused stronger but still insignificant increase of the Falling number (measurement accuracy $\pm 10 \%[9]$ ).

\subsection{Flours and Composites Pasting}

\section{Amylograph test results}

For the wheat control, course of the amylograph curve was typical for such type of wheat flour produced in the Czech Republic (Fig. 2a). Viscous behaviour of canahua flour pointed to two-stage gelatinization, which did not prolonged time of the viscosity maximum. Compared to this, viscosity of quinoa flour suspension rose up directly (Fig. 2b). During the amylograph test, both alternative flour samples demonstrated statistically higher temperature of the gelatinization beginning than WF control.

Contrary to the results published by Pérez et al., no significant difference was observed between quinoa and canahua [4]. Due to amylograph maxima higher than amylograph technical limit 1000 BU, temperature assigned to the viscosity maximum could be derived from the readings approximately (Fig. 2). For quinoa and canahua wholemeals, the temperature belonging to the viscosity maxima reached probably higher levels than for $\mathrm{WF}\left(>87\right.$ and $>99{ }^{\circ} \mathrm{C}$ vs. range $88-94{ }^{\circ} \mathrm{C}$, respectively; Table 1 ). Gelatinization of the quinoa flour composites started later than in case of the canahua counterparts did, 
and the difference in temperatures rose up to about $10^{\circ} \mathrm{C}$. For the temperatures of viscosity maximum, this tendency was maintained, and for both more enriched samples, values were softly lower. Also for the foursome of tested wheat-quinoa and wheat-canahua composites, amylograph viscosity maxima were higher than 1000 BU (i.e. unevaluable).

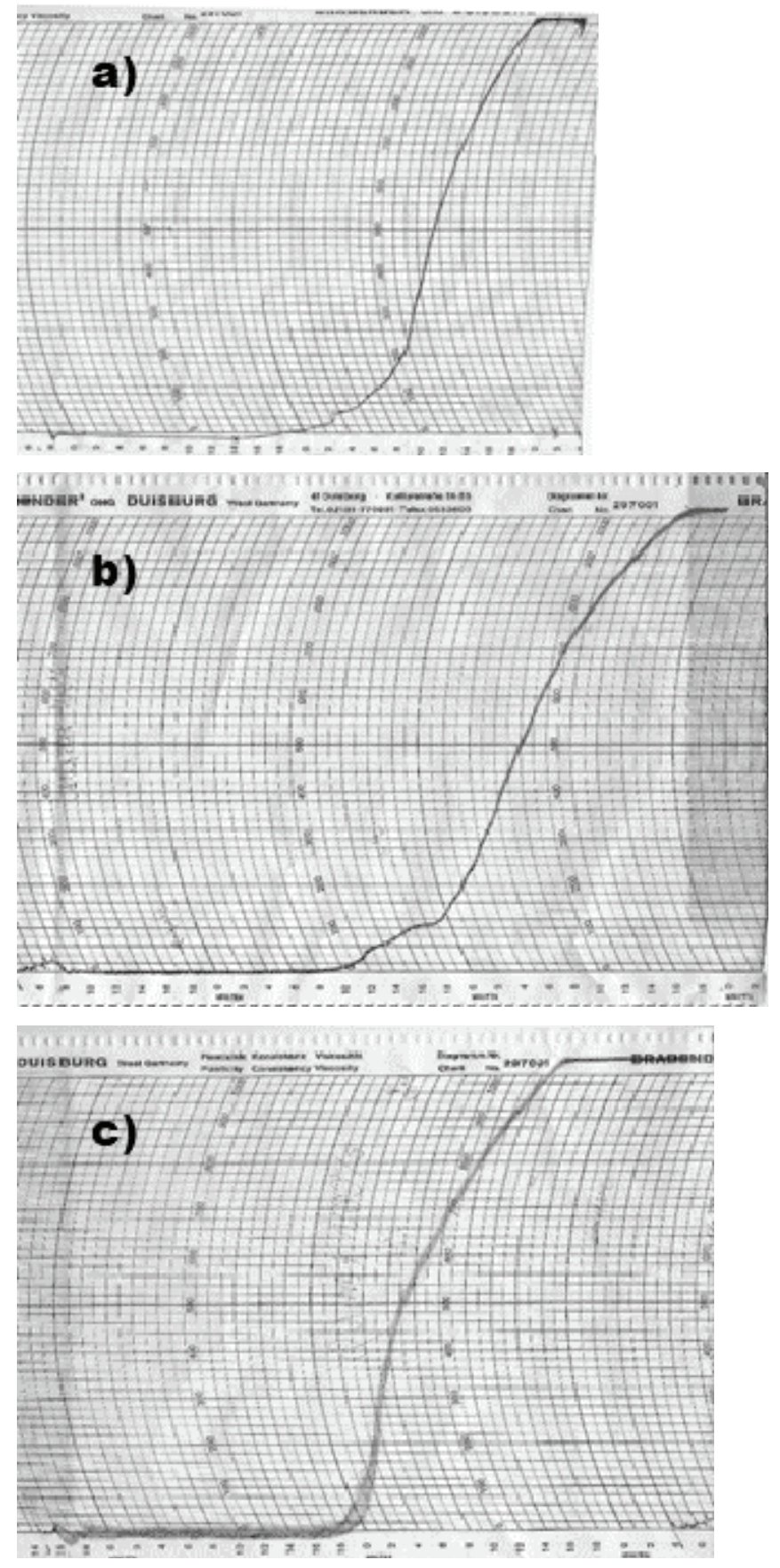

Figure 2. Amylograph curves for a) wheat flour, b) canahua wholemeal and c) quinoa wholemeal. 
Table 1. Influence of cahanua and quinoa on amylograph characteristics of wheat flour

\begin{tabular}{|c|c|c|c|c|}
\hline Composite flour ${ }^{1}$ & $\begin{array}{c}\text { Temp. of gelatinization } \\
\text { beginning }\left({ }^{\circ} \mathrm{C}\right)^{3} \\
\end{array}$ & $\begin{array}{l}\text { Temp. of gelatinization } \\
\text { maximum }\left({ }^{\circ} \mathrm{C}\right)^{3}\end{array}$ & $\begin{array}{r}\text { Amylograph } \\
(\mathrm{BU} \\
\end{array}$ & $\begin{array}{l}\text { maximum } \\
{ }^{2,3}\end{array}$ \\
\hline $\mathrm{WF}$ & $49.0 \quad \mathrm{a}$ & $88-94 \quad a$ & $>1000$ & n.e. \\
\hline $\mathrm{C}$ & $58.0 \mathrm{~d}$ & $>97 \mathrm{c}$ & $>1000$ & n.e. \\
\hline WFC10 & 53.2 b & $91-93$ a & $>1000$ & n.e. \\
\hline WFC20 & $55.0 \mathrm{bc}$ & $90-95 \quad a b$ & $>1000$ & n.e. \\
\hline $\mathrm{Q}$ & $57.3 \mathrm{~cd}$ & $>87$ n.e. & $>1000$ & n.e. \\
\hline WFQ10 & $62.2 \mathrm{e}$ & $91-96 \quad b$ & $>1000$ & n.e. \\
\hline WFQ20 & $61.6 \mathrm{e}$ & $90-96 \mathrm{ab}$ & $>1000$ & n.e. \\
\hline
\end{tabular}

${ }^{1}$ Flour samples: WF - wheat, Q - quinoa, C - canahua one; Flour composites: WFC10, WFC20, WFQ10, WFQ20 -

wheat-canahua/quinoa blends 90:10 and 80:20 (w/w), respectively

${ }^{2} \mathrm{BU}$ : Brabender unit

${ }^{3}$ a-e: values signified by the same letter are not statistically different (HSD test, $p>0.05$ ); n.e.: non-evaluable.

\section{RVA profiles}

Comparing the RVA profiles of WF, canahua and quinoa, a clear difference was recorded (Fig. 3a, 3b, 3e, respectively). Wheat starch size distribution comprises about $90 \mathrm{wt}$. \% of A-granules (size 10-40 $\mu \mathrm{m}$ ) and 10 wt. $\%$ of B-ones (diameter $\approx 10 \mu \mathrm{m}$ ). Bechtel and Wilson discerned also C-type of granules, lower than $5 \mu \mathrm{m}$ [12]. As mentioned supra, starch of both canahua and quinoa is characterised by diverse distribution - small granules represent a majority in starch mass. Within both profiles, viscosity points Peak viscosity and Hold viscosity could not be identified clearly.

Similar RVA profile recorded Ragaee \& Abdel-Aal for the cereal sorghum [13]. In sorghum grains, small granules of B-type (or B- and C-types) form $60-68$ vol. $\%$ of starch. Authors stated that in comparison to the other cereals tested, sorghum sample required a longer time to reach maximal viscosity due to lower rate of the hydration and swelling of starch granules. As the Hold viscosity measures viscosity of disrupted starch particle under shear and heat, damage of quinoa as well as canahua starch did not occur as fast as wheat one and suspensions viscosity rose almost continually. During the mixolab test, higher temperature for complete pasting of the qunioa starch was observed compared to wheat one [2]. Further, pure canahua flour gave a very low torque during heating phase of the test, indicating very low extent of the starch gelatinization. At the end of the RVA test, viscosity depended also on sample type - with exception of the canahua, values were elevated onto higher level than the Peak Viscosity. For praxis, it could mean slower aging of cereal products containing canahua, based on lower starch retrogradation rate.

Table 2. Comparison of RVA parameters for wheat, quinoa, canahua flours and wheat bi-composites

\begin{tabular}{ccccccc}
\hline $\begin{array}{c}\text { Composite } \\
\text { flour }{ }^{1}\end{array}$ & $\begin{array}{c}\text { PeakTemp } \\
\left({ }^{\circ} \mathrm{C}\right)^{2}\end{array}$ & $\begin{array}{c}\text { PeakTime } \\
(\mathrm{min})^{2}\end{array}$ & $\begin{array}{c}\text { PeakVisc } \\
(\mathrm{mPa} \mathrm{s})^{2}\end{array}$ & $\begin{array}{c}\text { HoldTime } \\
(\mathrm{min})^{2}\end{array}$ & $\begin{array}{c}\text { HoldVisc } \\
(\mathrm{mPa} \mathrm{s})^{2}\end{array}$ & $\begin{array}{c}\text { FinalVisc } \\
(\mathrm{mPa} \mathrm{s})^{2}\end{array}$ \\
\hline WF & $87.3 \mathrm{~b}$ & $6.07 \mathrm{a}$ & $2171 \mathrm{~d}$ & $8.13 \mathrm{~b}$ & $1320 \mathrm{~b}$ & $2952 \mathrm{c}$ \\
\hline $\mathrm{C}$ & $87.2 \mathrm{~b}$ & $5.80 \mathrm{a}$ & $547 \mathrm{a}$ & $6.73 \mathrm{a}$ & $528 \mathrm{a}$ & $553 \mathrm{a}$ \\
\hline WFC10 & $87.2 \mathrm{~b}$ & $6.00 \mathrm{a}$ & $2010 \mathrm{~b}$ & $8.07 \mathrm{~b}$ & $1278 \mathrm{~b}$ & $2790 \mathrm{c}$ \\
WFC20 & $86.4 \mathrm{~b}$ & $5.87 \mathrm{a}$ & $1920 \mathrm{~b}$ & $8.13 \mathrm{~b}$ & $1294 \mathrm{~b}$ & $2801 \mathrm{c}$ \\
\hline $\mathrm{Q}$ & $79.9 \mathrm{a}$ & $6.40 \mathrm{~b}$ & $1368 \mathrm{~cd}$ & $n . e$. & $n . e$. & $1945 \mathrm{~b}$ \\
\hline WFQ10 & $86.5 \mathrm{~b}$ & $6.07 \mathrm{a}$ & $2034 \mathrm{~cd}$ & $8.13 \mathrm{~b}$ & $1314 \mathrm{~b}$ & $2856 \mathrm{c}$ \\
WFQ20 & $86.5 \mathrm{~b}$ & $6.00 \mathrm{a}$ & $1947 \mathrm{~b}$ & $8.07 \mathrm{~b}$ & $1339 \mathrm{~b}$ & $2777 \mathrm{c}$ \\
\hline
\end{tabular}

${ }^{1}$ Flour samples: WF - wheat, Q - quinoa, C - canahua one; Flour composites: WFC10, WFC20, WFQ10, WFQ20 - wheatcanahua/quinoa blends 90:10 and 80:20, respectively.

2 a-d: values signified by the same letter are not statistically different (HSD test, $p>0.05$ ).

n.e.: non-evaluable

Course of the RVA profiles of the bi-composites containing canahua and quinoa corresponded with 
the control one, i.e. nor $20 \%$ replacement of WF did not lead to broader variation in pasting behaviour (Fig. 3c-3d, 3f-3g). There could be noticed, the higher portion of the alternative materials, the lower Peak Viscosities; a decrease reached 7 and $11 \%$ in average. Hold Viscosity of the canahua blends were insignificantly lower about $40 \mathrm{mPa}$, while values for the quinoa counterparts were comparable to the control (Table 2). Besides this finding, the Final Viscosity points were statistically similar among the control flour and the bi-composites foursome. Rosell et al. confirmed analogous rheological behaviour of wheat-quinoa and wheat-canahua doughs up to $50 \%$ portion of the alternative materials in blend [2].
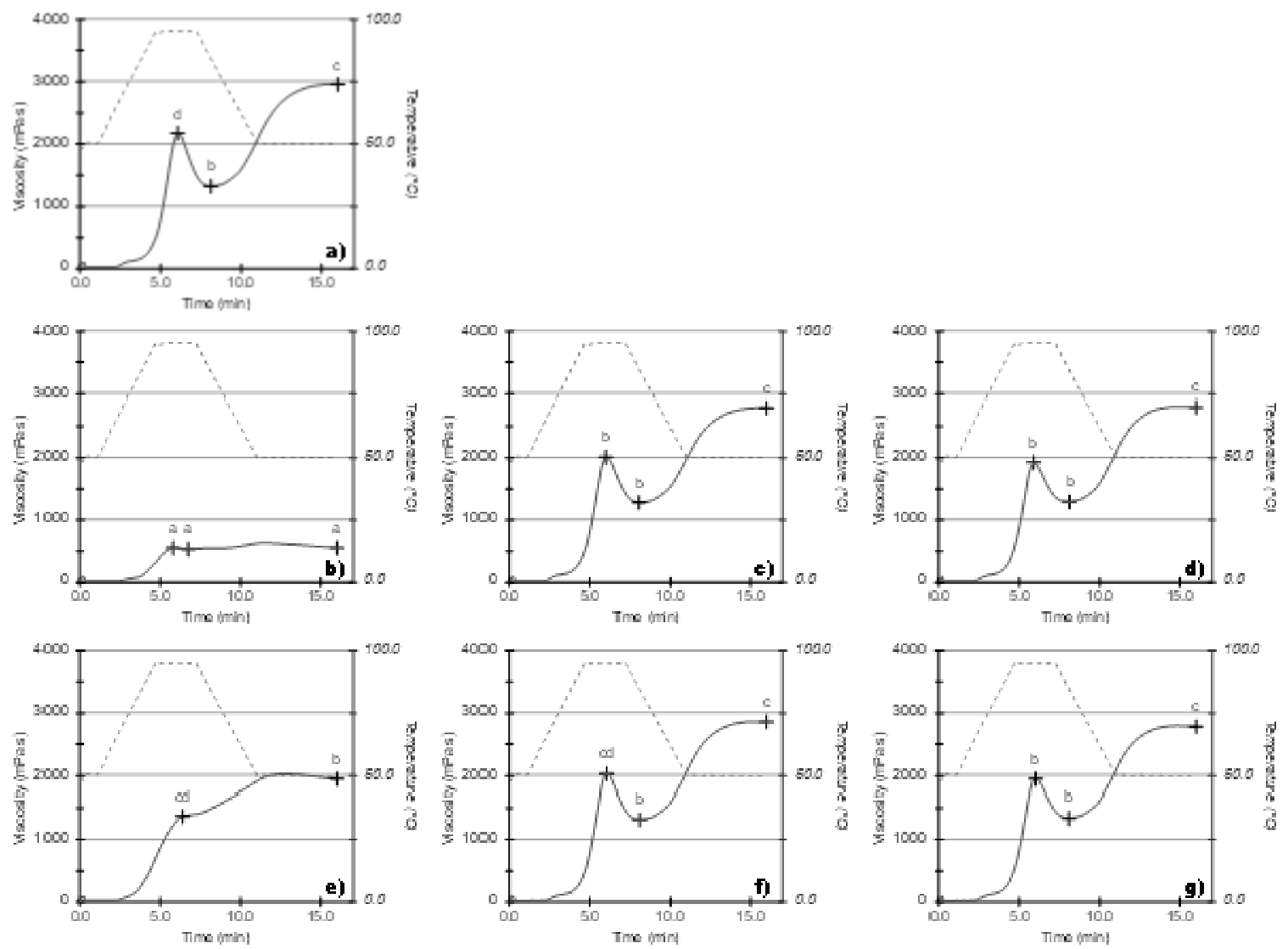

Figure 3. Comparison of RVA profiles of tested flour samples and flour composites. a) wheat flour (WF), b) canahua flour (C), c) WFC10, d) WFC20, e) quinoa (Q), f) WFQ10, g) WFQ20 (non-traditional materials dosage 10 or 20 wt. \%, respectively). From left to right, crossed denote curve points Peak Viscosity, Hold Viscosity and Final Viscosity, respectively (for quinoa flour (plot e)), Hold Viscosity unevaluable). a-d: viscosity points signed by the same letter are not statistically different $(p>0.05)$

\subsection{Principal Component Analysis}

Within dataset combining 13 qualitative parameters and 7 tested samples, the first two principal components explained $85 \%$ of data scatter; PC1 contributed by $58 \%$ and PC2 by $27 \%$ (Fig. 4). The multivariate biplot is usually interpreted into two meanings - in terms of reciprocal alteration of the recorded quality features and samples statistical similarity.

In Fig. 4, together five clusters among quality characteristics could be found. Both operational analytical features Zeleny test and Falling number have outstanding position, based on higher values for pure canahua and quinoa wholemeals than for the WF. Joining the amylograph maximum (AMA) and a pair of the RVA characteristics Peak Viscosity and Final Viscosity together confirms a key importance of the viscosity maximum during heating phase of the both tests. Closeness of the Breakdown and the Setback to the Peak Viscosity, the Hold Viscosity and the Final Viscosity is based on mathematical derivation of the former two features from the latter ones (e.g. Breakdown = Peak Viscosity - Hold 
Viscosity). To describe pasting behaviour of tested samples completely, temperature (or time) immanent to the viscosity maximum should not be omitted, although modification of the blends composition did not vary scatter of the feature to a higher extent.

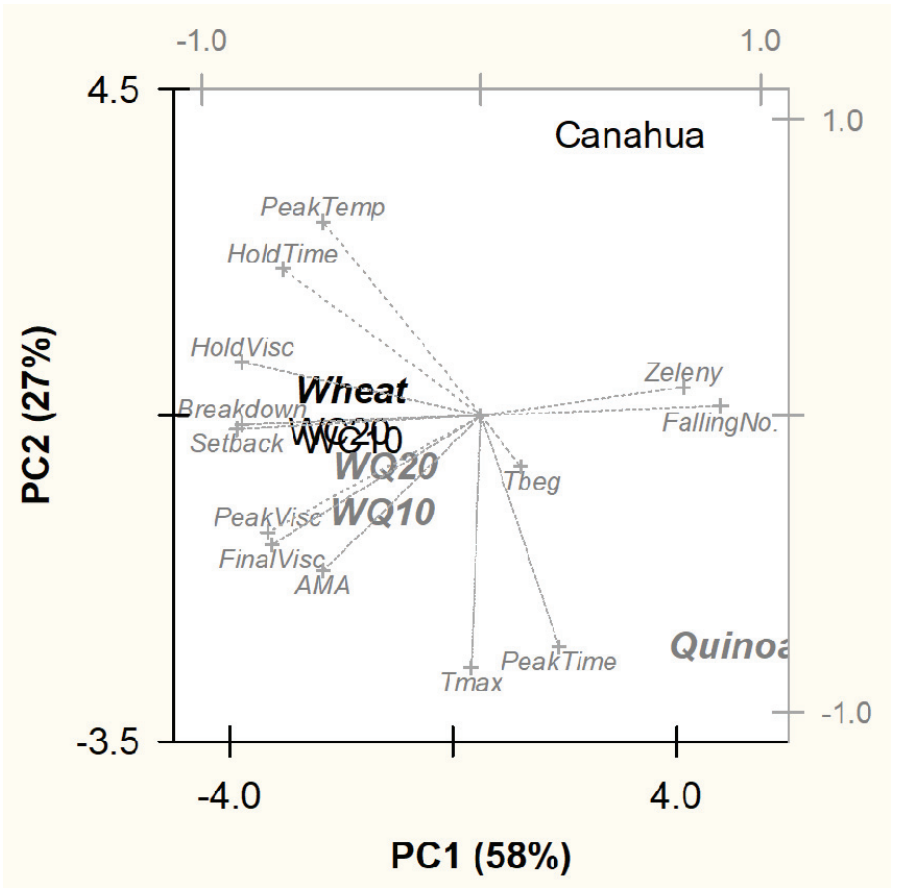

Figure 4. Biplot of principal components (PC) of qualitative features, tested flour types and flour composites.

A reciprocal position of the tested samples WF, canahua and quinoa predetermine coordinates of the bi-composite samples. Somewhat longer distance between WF - quinoa than WF - canahua meant better differentiation of the wheat-quinoa composites WFQ10 and WFQ20. Pasting behaviour of the bicomposite pair differed from the quinoa counterparts mainly in the Peak Time and the Peak Viscosity points.

\section{Conclusion}

Testing of the pasting properties of wheat flour and two botanical relatives canahua and quinoa confirmed differences between cereal and both pseudocereals behaviour. Diverse progress of gelatinization was based on a different size distribution of starch granules as well as on different amylose content. Using the amylograph apparatus, tested samples were distinguished in part compared to the Rapid Visco Analyser results. Though the latter test describes each sample by twice-higher amount of data, principal component analysis confirmed a key meaning of the pasting temperature, the peak time and the viscosity maximum comparably to the amylograph test. Progress of gelatinization was unlike between the canahua and the quinoa - canahua starch did not demonstrate a significant rate of retrogradation. Due to that, incorporation of canahua wholemeal into recipes of cereal products could likely slowed aging of such baked products and thereby prolonged their shelf life.

Acknowledgments. This study was supported by grant of the National Agency for Agricultural Research, Czech Republic (No. QI111 B053 'New Food').

\section{References}

1. A. Vega-Gálvez, M. Miranda, J. Vergara, E. Uribe, L. Puente and E.A. Martínez, "Nutrition facts and functional potential of quinoa (Chenopodium quinoa Willd.), an ancient Andean grain: a review". Journal of the science of 
food and agriculture, vol. 90, no. 15 pp. 2541-2547, 2010.

2. M. Rosell, G. Cortez and R. Repo-Carrasco, "Breadmaking use of the Andean crops quinoa (Chenopodium quinoa), kañiwa (Chenopodium pallidicaule), kiwicha (Amaranthus caudatus), and tarwi (Lupinus mutabilis)", Cereal Chemistry, vol. 86, no. 4, pp 386-392, 2009.

3. .T. K. Lim, "Chenopodium quinoa", in Edible medicinal and non-medicinal plants, Springer Netherlands, Dordrecht, Netherland, 2013, vol. 5, p. 817-819.

4. G. T. Pérez, M. E. Steffolani and A. E. León, "Canahua: An Ancient Grain for New Foods", in Functional properties of traditional foods, K. Kristbergsson and S. Ötles (Eds.), Springer US, Boston, USA, 2016, p. 265-267.

5. FAO (2018): http://www. fao. org/quinoa/en/. Accessed 20. 06. 2018.

6. F. Bavec and M. Bavec, "Organic production and use of alternative crops", Taylor Francis Group, New York, USA, 2007, p. 120

7. M. E. Steffolani, A. E. León and G. T. Pérez, "Study of the physicochemical and functional characterization of quinoa and kañiwa starches", Starch/Stärke, vol. 65, no. 11-12, pp. 976-983, 2013.

8. EN ISO 5529: Wheat - Determination of the sedimentation index - Zeleny test (2011)

9. EN ISO 3039: Wheat, rye and their flours, durum wheat and durum wheat semolina -- Determination of the falling number according to Hagberg-Perten (2009)

10.M. Jancurová, L. Minarovičová and A. Dandár, "Rheological properties of doughs with buckwheat and quinoa additives", Chemical Papers, vol. 63, no. 6, 738-741, 2009.

11.M. Pellegrini, R. Lucas-Gonzales, A. Ricci, J. Fontecha, J. Fernández-López, J. A. Pérez-Álvarez and M. ViudaMartos, "Chemical, fatty acid, polyphenolic profile, techno-functional and antioxidant properties of flours obtained from quinoa (Chenopodium quinoa Willd.) seeds", Industrial Crops and Products, vol. 111, pp. 38-46, 2018.

12.B. Bechtel, J. D. Wilson, "Ultrastructure of developing hard and soft red winter wheats after air- and freezedrying and its relationship to endosperm texture", Cereal Chemistry, vol. 74, no. 3, 235-241, 1997.

13.S. Ragaee and E. S. M. Abdel-Aal, "Pasting properties of starch and protein in selected cereals and quality of their food products", Food Chemistry, vol. 95, no. 1, 9-18, 2006. 